\title{
Alternative medicine loses its champion
}

Granting credibility to studies on alternative medicine-acupuncture, chelation therapy and the like-is hard enough at the best of times. The US National Institutes of Health (NIH) is about to find out how much tougher it can get with the loss of Stephen Straus, who has for seven years o overseen that research.

Citing health reasons, Straus in November announced his resignation as director of the NIH's National Center for Complementary and Alternative Medicine. He is to take on a role as senior adviser to NIH director Elias Zerhouni.

The NIH has set up a committee to find a replacement, but filling Straus' shoes won't be easy. He achieved what few thought possible when he took the job in 1999: a modicum of respect for the center from scientists who normally have little patience for alternative remedies.

Even Harold Varmus, who was the NIH director in 1999, initially opposed the center's creation. But when Congress ignored him and elevated the NIH's Office of Alternative Medicine, created in 1992, from second-tier status to a center with all the powers and prerogatives of other NIH institutes, Varmus hired Straus, a virologist and immunologist, to lead the center.

"Steve has a high degree of scientific acumen and he brought real science to the conduct of the center," Varmus says.

Straus doesn't shy away from that characterization. "We and NIH built a complementary and alternative medicine research enterprise that is the model for the world," he said in an emailed comment.

The center's budget has grown from $\$ 50$ million in 1999 to nearly $\$ 123$ million in 2006. Including projects with other institutes, alternative medicine research in 2004 accounted for $\$ 305$ million in NIH funds.

Straus has also garnered plaudits as a bridgebuilder between alternative therapists and mainstream biomedical scientists.

"There was great distrust in both communities at the beginning of the adventure," says Massachusetts General Hospital researcher Bruce Rosen, who has a grant to study the effects of acupuncture on the brain using neuroimaging. "It's clear [Straus] was really able to pull them together."

Nonetheless, many scientists continue to view the center as conferring money and respectability on nostrums that deserve neither. In July Arthur Grollman, a clinical pharmacologist at the State University of New York at Stony Brook, and a colleague published a commentary chastising the center for funding proposals "of dubious merit," and calling for an Institute of Medicine committee to evaluate its charter and research portfolio (Science 313, 301-304).

Writing in the same issue of Science, Straus shot back that many criticisms of his institute are

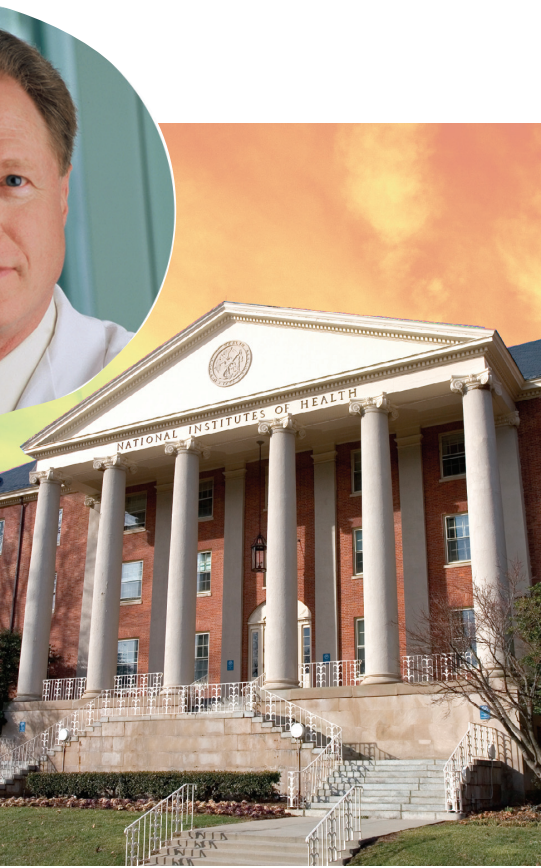

Fringe loss: Stephen Straus (inset) has resigned as director of the US National Center for Complementary and Alternative Medicine.

"misinformed." He noted that nearly two-thirds of Americans report using alternative therapies. "The public is using [these] without proof of efficacy or safety, which is the very reason that [this] research is so important."

Grollman is unconvinced. The center spends millions of dollars on clinical trials of questionable alternative remedies such as shark cartilage, he says. "We do not believe this is justified when at the same time they are funding NIH grants at distressingly low levels."

Meredith Wadman, Washington DC

\section{Europe's sweeping chemical law puts medicines in peril}

The European Union is set to require extensive testing of nearly every chemical used in manufacturing. The rules could bring many medicines on the market up for reapproval, but few companies are prepared to deal with the fallout.

Known as REACH - the framework for the Registration, Evaluation and Authorization of Chemicals - the rules require companies to provide safety and handling information on every chemical they make. That information is not available for more than $90 \%$ of chemicals used.

Although the regulations, which go into effect April 2007, have been eight years in the making, "companies are only waking up about [the rules]," says Steffen Erler, a consultant for REACHReady, a UK-based industry group that gives advice on meeting the requirements.

The active ingredients in drugs are largely exempt from the rules, but other materials used in drug manufacturing - such as solvents, reagents, cleaners and drug precursors-will need to be registered within 18 months of the regulation's enactment.

The reporting requirements and high registration costs may force manufacturers to withdraw their chemicals from the market, says Dirk Frenzel, a spokesman for the Germanybased drugmaker Bayer.

Pharmaceutical companies will then have to find new suppliers, or substitute chemicals for those taken off the market. Any new formulations will need to be resubmitted for approval, which could take months.

"There will be bumps," says Guy Villax, chief executive officer of Hovione, a Portugal-based manufacturer of drug ingredients.

There are no estimates of the rules' potential impact, but pharmaceutical giant AstraZeneca says at least two of its drugs may need reapproval. Other companies say they're preparing for the rules, but decline to specify whether individual drugs could be threatened.

"We're identifying all key raw materials and contacting the suppliers. We need to find out whether all the chemicals we use will still be on the market," says Michael Laub, a communications officer at Denmark-based NovoNordisk.

Though drugs exported to Europe won't need to be registered, approximately $80 \%$ of ingredients in US-made drugs are imported-many from Europe. Drug makers in the US appear less prepared than their European counterparts.

"We haven't really thought about this," says Mark Grayson, a spokesman for the Pharmaceutical Manufacturers of America, the industry's trade organization.

Attempts by the US government and the chemical industry to fight the rules have slowed down the preparations even further, says Darryl Ditz, a senior policy advisor at the Center for International Environmental Law, a Washington DC-based think tank. "The government and US trade associations are behind the curve."

Brandon Keim, New York 